\title{
Anti-obesity effects of Geranium thunbergii extract via improvement of lipid metabolism in high-fat diet-induced obese mice
}

\author{
YOON-YOUNG SUNG, TAESOOK YOON, WON-KYUNG YANG, SEUNG JU KIM and HO KYOUNG KIM \\ Center of Herbal Resources Research, Korea Institute of Oriental Medicine, \\ Yuseong-gu, Daejeon 305-811, Republic of Korea
}

Received June 1, 2011; Accepted August 8, 2011

DOI: $10.3892 / \mathrm{mmr} .2011 .568$

\begin{abstract}
This study investigated the anti-obesity properties of an extract of Geranium thunbergii (GTE) in high-fat diet-induced obese mice. GTE treatment significantly reduced body weight, adipose tissue mass, adipocyte size, as well as serum triglyceride, total cholesterol and low-density lipoprotein-cholesterol levels in obese mice compared to high-fat diet-fed mice. It also decreased serum leptin levels and increased adiponectin levels. The serum levels of aspartate transaminase, alanine transaminase, blood urea nitrogen and creatinine were not significantly changed in GTE-treated mice compared to serum levels in normal diet and high-fat diet-fed mice. Furthermore, GTE suppressed the mRNA levels of sterol regulatory element-binding protein 1c, peroxisome proliferator-activated receptor $\gamma$, adipocyte fatty acid-binding protein and fatty acid synthase in the adipose tissues of obese mice. These results suggest that GTE ameliorated high-fat diet-induced obesity by altering the adipokine levels and downregulating the expression of transcription factors and lipogenic enzymes involved in lipid metabolism.
\end{abstract}

Correspondence to: Dr Ho Kyoung Kim, Center of Herbal Resources Research, Korea Institute of Oriental Medicine, 483 Exporo, Yuseong-gu, Daejeon 305-811, Republic of Korea E-mail: hkkim@kiom.re.kr

Abbreviations: ALT, alanine transaminase; aP2, adipocyte fatty acid-binding protein; AST, aspartate transaminase; C/EBP, CCAAT/enhancer binding protein; FAS, fatty acid synthase; FER, food efficiency ratio; GAPDH, glyceraldehyde-3-phosphate dehydrogenase; GTE, Geranium thunbergii extract; HDL, High density lipoprotein; HFD, high-fat diet; LDL, low density lipoprotein; ND, normal diet; PPAR, peroxisome proliferator-activated receptor; SREBP, sterol regulatory element-binding protein

Key words: body weight, cholesterol, Geranium thunbergii, leptin, obesity

\section{Introduction}

Obesity accelerates the accumulation of excess fat, which is caused by an imbalance between energy intake and expenditure (1). Obesity is associated with additional metabolic diseases, such as dyslipidemia, type 2 diabetes mellitus, hypertension, stroke and arteriosclerosis (2), and is characterized by increased adipose tissue mass, which results from increased adipose cell size and number (3). Adipocyte size is determined by the amount of lipid that accumulates in adipose tissue, which is regulated by various enzymes such as fatty acid synthase (FAS), adipocyte fatty acid-binding protein (aP2), and lipoprotein lipase (LPL). During adipose tissue development, three major transcription factors, peroxisome proliferator-activated receptor (PPAR) $\gamma, \mathrm{CCAAT/enhancer} \mathrm{binding} \mathrm{protein}(\mathrm{C} / \mathrm{EBP})$ $\alpha$, and sterol regulatory element-binding protein (SREBP) 1c, regulate the expression of these lipid-metabolizing enzymes (4).

To treat obesity, various pharmacological approaches, including drugs, have been suggested to control lipid uptake or appetite. However, these pharmacological agents have been reported to cause undesirable adverse effects such as constipation, insomnia, vomiting, headache, stomachache and heart failure (5-6). Therefore, there is a demand for therapeutically effective and safe anti-obesity agents. In previous studies, numerous oriental medicinal herbs were reported to be useful for controlling obesity and hyperlipidemia without significant side effects (7-8).

Geranium thunbergii, which belongs to the family of Geraniaceae, is a perennial plant that is found in Korea, China and Japan. The plant has traditionally been used as an anti-diarrhetic agent in East Asia (9). Moreover, it has been reported to exhibit anti-mutagenic, anti-inflammatory, and anti-oxidative effects (10-12). One of the representative tannin in Geraniaceae, geraniin, has been shown to have antihypertensive, anti-bacterial and anti-fungal properties (13-14). However, no studies are currently available regarding the antiobesity effects of Geranium thunbergii. In the present study, the effects of a $70 \%$ ethanol extract of Geranium thunbergii (GTE) on body weight, fat mass and serum lipid levels in high fat-diet-induced obese mice were examined. Furthermore, the mRNA expression levels of lipid accumulation-related genes in adipose tissue were investigated. 


\section{Materials and methods}

Preparation of GTE. Geranium thunbergii was purchased as a dried herb from Omniherb Co. (Yeoungcheon, Korea) and was authenticated based on its microscopic and macroscopic characteristics by the Classification and Identification Committee of the Korea Institute of Oriental Medicine (KIOM). The committee comprised nine experts in the fields of plant taxonomy, botany, pharmacognosy, and herbology. A voucher specimen (no. JA-109) was deposited at the herbarium of the Department of Herbal Resources Research in KIOM. The dried leaves of Geranium thunbergii (100 g) were extracted twice with $70 \%$ ethanol (with $2 \mathrm{~h}$ reflux) and the extract was then concentrated under reduced pressure. The decoction was filtered, lyophilized and serially stored at $4^{\circ} \mathrm{C}$. The yield of the dried extract from starting crude materials was approximately $22.08 \%(\mathrm{w} / \mathrm{w})$.

Animals and diets. Male 4-week-old C57BL/6J mice were purchased from Daehan Biolink Co. (Eumsung, Korea) and were maintained for 1 week prior to the experiment. The animals were housed in an air-conditioned room with a 12-h light/dark cycle at a temperature of $22 \pm 1^{\circ} \mathrm{C}$ and humidity of $50 \pm 10 \%$. Mice were provided with a laboratory diet and water ad libitum. All experimental protocols involving the use of animals were conducted in accordance with the National Institutes of Health (NIH) guidelines and approved by the Committee on Animal Care of our institute. For induction of obesity, the mice were fed a high-fat diet (HFD) (Rodent diet D12492, Research diet, New Brunswick, NJ, USA) consisting of $60 \%$ of energy as fat, $20 \%$ as protein and $20 \%$ as carbohydrates, in accordance with previously published reports (15). Normal mice were fed a commercial standard chow diet (Orient Bio Inc., Seongnam, Korea) consisting of $14 \%$ of energy as fat, $21 \%$ as protein and $65 \%$ as carbohydrates. The mice were randomly divided into three groups $(\mathrm{n}=6)$ and respectively fed a normal diet (ND), HFD, and HFD plus GTE (HFD+GTE) for 6.5 weeks. GTE was dissolved in normal saline and was orally administered to the mice at a dose of $400 \mathrm{mg} / \mathrm{kg} / \mathrm{day}$ for 6.5 weeks. The dose of GTE used in these experiments was determined from preliminary dose-range experiments and from previously published reports (16). By contrast, saline was orally administered to mice in the ND and HFD control groups. Body weight and food intake were measured twice a week.

Biochemical analysis of blood. At the end of the experimental period, the mice were fasted prior to being sacrificed. The mice were anesthetized with ether and then blood samples were obtained from the inferior vena cava of each mouse. Blood samples were centrifuged at 2,500 rpm for $15 \mathrm{~min}$ at $4^{\circ} \mathrm{C}$, and serum was obtained and stored at $-70^{\circ} \mathrm{C}$ prior to analysis. Serum levels of triglycerides, total cholesterol, low density lipoprotein (LDL)-cholesterol, high density lipoprotein (HDL)-cholesterol, aspartate transaminase (AST), alanine transaminase (ALT), blood urea nitrogen and creatinine were analyzed with an automatic analyzer (Hitachi 7080, Hitachi Co., Tokyo, Japan). The concentration of serum leptin and adiponectin was measured with mouse leptin and adiponectin ELISA kits (R\&D Systems, Minneapolis, MN, USA), respectively, according to the manufacturer's instructions. The absorbance was measured using a microplate spectrophotometer (BioRad, Hercules, CA, USA).

Adipose tissue weight and histologic analysis. Following blood collection, the white adipose tissues (subcutaneous, epididymal and retroperitoneal) were removed from mice and weighed immediately. For adipocyte staining, adipose tissues were fixed in $10 \%$ neutral formalin solution for 1 day and embedded in paraffin. The tissues were cut at a thickness of $6 \mu \mathrm{m}$ and stained with hematoxylin and eosin. To quantitate adipocyte size, the stained sections were analyzed using light microscopy (Olympus BX51, Olympus Optical Co., Tokyo, Japan) and an image analysis program (Image pro plus 5.0, Media Cybernetics, Silver Spring, MD, USA).

Reverse transcriptase-polymerase chain reaction (RT-PCR). Tissue was homogenized, and total RNA was isolated with the easy-BLUE total RNA extraction kit (Intron, Seoul, Korea) according to the manufacturer's instructions. For cDNA synthesis, $1 \mu \mathrm{g}$ of total RNA was mixed with premix containing oligo (dT) primer and DEPC-treated water at a final volume of $20 \mu \mathrm{l}$ and incubated at $45^{\circ} \mathrm{C}$ for $60 \mathrm{~min}$. The reaction was stopped by heat inactivation at $95^{\circ} \mathrm{C}$ for $5 \mathrm{~min}$. cDNAs were then amplified with gene-specific primers using the Taq PCR master mix (Qiagen, Tokyo, Japan) according to the manufacturer's instructions. The $20 \mu \mathrm{l}$ amplification mixture contained $1 \mu \mathrm{l}$ of cDNA, $10 \mu \mathrm{l}$ of $2 \mathrm{X}$ Taq PCR master mix containing $1.5 \mathrm{mM} \mathrm{MgCl}, 0.1 \mu \mathrm{M}$ of each primer, and water. After a 15 min preincubation at $94^{\circ} \mathrm{C}$, PCR amplification was performed for 35 cycles with the following cycling conditions: $30 \mathrm{sec}$ of denaturation at $94^{\circ} \mathrm{C}, 30 \mathrm{sec}$ of annealing at $60^{\circ} \mathrm{C}$ and $1 \mathrm{~min}$ of extension at $72^{\circ} \mathrm{C}$. Primers were designed using Primer 3 software, and the sequences are available in the GenBank database. Table I shows the sequences of the genespecific PCR primers. The relative expression levels of target genes were normalized using GAPDH as an internal control.

Statistical analysis. Differences between groups were examined using analysis of variance (ANOVA) followed by Duncan's multiple range test. Data are presented as the means \pm SE. Significant differences were accepted when $p<0.05$.

\section{Results}

Body weight and food intake. The average body weight, body weight gain and food intake of the mice in the three treatment groups are shown in Fig. 1A and Table II. The final body weight of the HFD group was significantly higher than that of the ND group. However, HFD+GTE mice had a $13 \%$ lower body weight than HFD-fed mice. Body weight gain was markedly lower in the GTE-treated group compared to the HFD group. Additionally, GTE did not affect food intake. The food intake was not decreased in the HFD+GTE group compared to the HFD group. These results indicate that the reduction of body weight gain by the treatment of GTE did not depend upon a decreased food intake, since no difference was observed between control and experimental groups in food intake.

Weights and histology of adipose tissue. To investigate whether GTE decreases adiposity, mice were sacrificed and 
Table I. Primer sequences used in the RT-PCR analysis.

\begin{tabular}{lcccc}
\hline Genes & \multicolumn{1}{c}{ Forward } & Reverse & Accession number & Length (bp) \\
\hline PPAR $\gamma$ & CCCTGGCAAAGCATTTGTAT & GAAACTGGCACCCTTGAAAA & NM_011146 & 225 \\
SREBP1c & AGCTCAAAGACCTGGTGGTG & TCATGCCCTCCATAGACACA & NM_011480 & 216 \\
FAS & CGCACCGGCTACCAAGCCAA & GCTTCCCGGGTTGCCCTGTC & NM_007988 & 266 \\
aP2 & TGGAAGCTTGTCTCCAGTGA & GCTCTTCACCTTCCTGTCGT & NM_024406 & 225 \\
\hline
\end{tabular}

Table II. Effects of Geranium thunbergii extract on body weight gain and food intake in high-fat diet-induced obese mice.

\begin{tabular}{lrrr}
\hline & ND & HFD & HFD+GTE \\
\hline Initial body weight $(\mathrm{g})$ & $21.06 \pm 0.30$ & $21.03 \pm 0.50$ & $21.21 \pm 0.33$ \\
Final body weight $(\mathrm{g})$ & $24.90 \pm 0.30$ & $30.85 \pm 0.95^{\mathrm{b}}$ & $26.89 \pm 0.75^{\mathrm{c}}$ \\
Body weight gain $^{\mathrm{a}}(\mathrm{g})$ & $3.84 \pm 0.23$ & $9.81 \pm 0.59^{\mathrm{b}}$ & $5.69 \pm 0.80^{\mathrm{c}}$ \\
Food intake (g/day) & $4.65 \pm 0.29$ & $2.50 \pm 0.07^{\mathrm{b}}$ & $2.41 \pm 0.08$ \\
\hline
\end{tabular}

${ }^{\text {aBody }}$ weight gain $=$ final body weight - initial body weight. Values are expressed as the means $\pm \mathrm{SE}(\mathrm{n}=6)$. Significant differences between the ND and HFD groups: ${ }^{b} \mathrm{p}<0.001$. Significant differences between the HFD and HFD+GTE groups: ${ }^{\mathrm{p}}<0.01$.

A

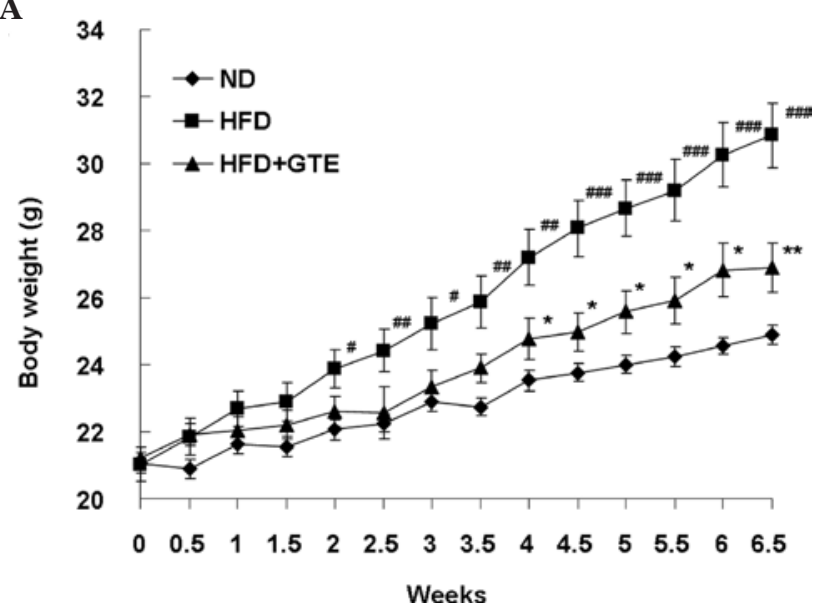

B

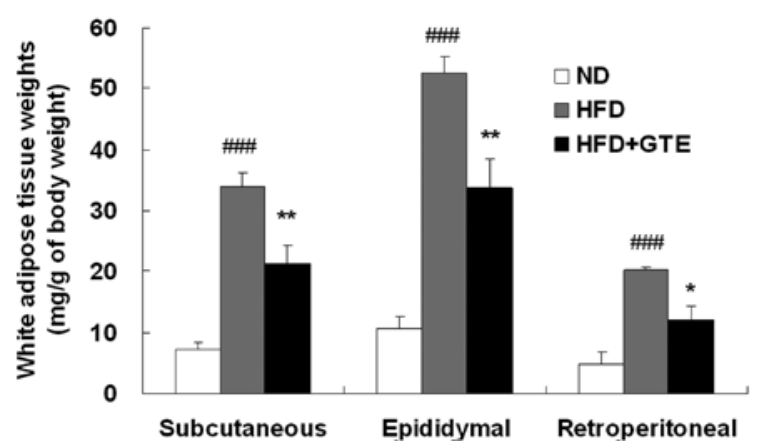

Figure 1. Effect of Geranium thunbergii extract on body weight and adipose tissue weight in obese mice fed a high-fat diet. GTE was administered orally to the mice at a dose of $400 \mathrm{mg} / \mathrm{kg} /$ day for 6.5 weeks. (A) Body weight and (B) white adipose tissue weight in high-fat diet-induced obese mice. ND, normal diet; HFD, high-fat diet; HFD+GTE, high fat diet + Geranium thunbergii extract. Values are expressed as the means \pm SE (n=6). Significant differences between the ND and HFD groups: ${ }^{\#} \mathrm{p}<0.05 ;{ }^{\# \#} \mathrm{p}<0.01$; and ${ }^{\# \# \#} \mathrm{p}<0.001$. Significant differences between the HFD and HFD+GTE groups: ${ }^{*}<<0.05$ and ${ }^{* *} \mathrm{p}<0.01$.

adipose tissues were removed and weighed. The weight of various white adipose tissues, including subcutaneous, epididymal and retroperitoneal, were increased in the HFD-fed mice compared to the ND-fed mice, and the weight of white adipose tissues was significantly decreased by the administration of GTE (Fig. 1B). Adipose tissues were further examined histologically (Fig. 2A). Adipocytes in subcutaneous, epididymal and retroperitoneal adipose tissues was notably higher in the HFD than in the ND group. Compared to adipocytes in the HFD-fed mice, GTE treatment significantly decreased adipocyte size in obese mice (Fig. 2B).

Serum lipid parameters and leptin and adiponectin levels. GTE treatment in HFD-fed mice significantly inhibited the HFD-induced increases in triglyceride, total cholesterol and LDL-cholesterol levels (Table III). However, HDL-cholesterol levels were not different between the HFD and HFD+GTE groups. HFD-fed mice had markedly higher serum leptin levels compared to the ND-fed mice. However, the GTE-treated group had decreased serum leptin levels compared to the HFD group (Fig. 3A). Conversely, GTE treatment significantly increased adiponectin levels in HFD-fed mice (Fig. 3B).

Assessment of potential toxicological effects. To evaluate potential toxic effects of ingesting GTE, serum toxicological markers, which indicate liver and kidney injury, were measured at the end of the experimental period. The levels of 
A

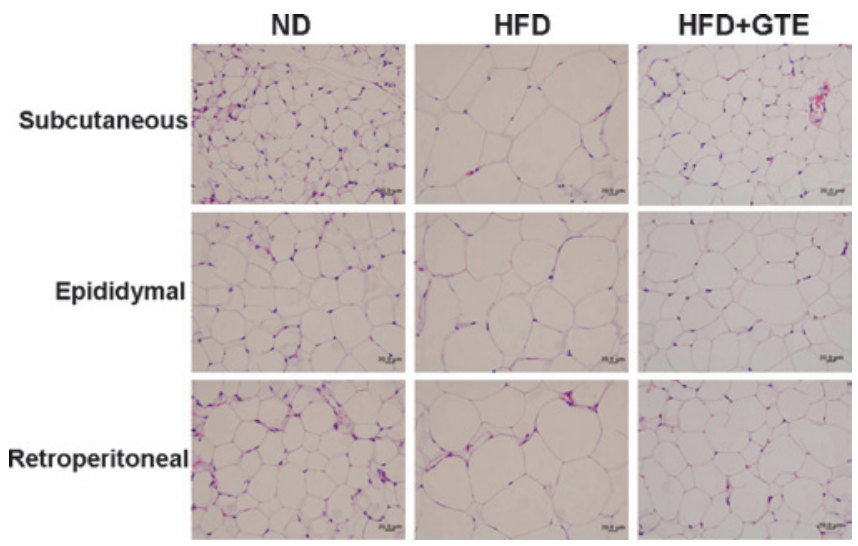

B

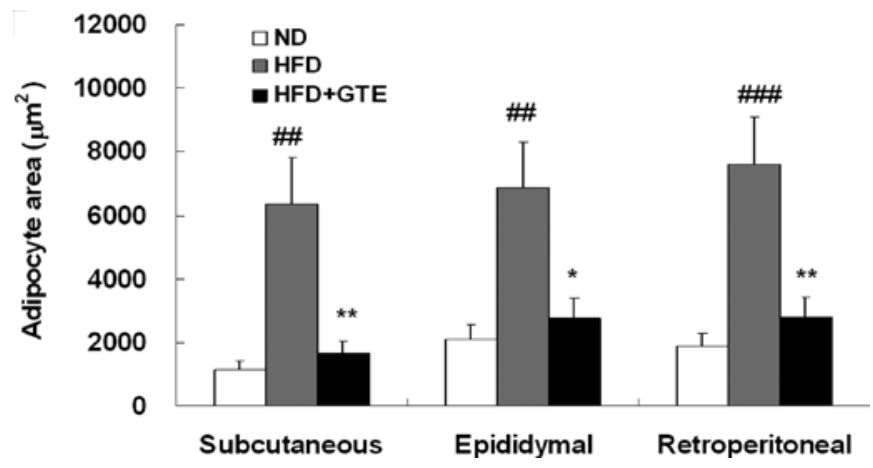

Figure 2. Histology of adipose tissues in high-fat diet-induced obese mice. (A) Representative images and (B) adipocyte area of hematoxylin and eosin-stained sections (magnification, x400). ND, normal diet; HFD, high-fat diet; HFD+GTE, high-fat diet + Geranium thunbergii extract. A total of 20 cells were measured for each mouse. Values are shown as the means \pm SE $(n=20)$. Significant differences between the ND and HFD groups: ${ }^{\# \#} p<0.01$ and ${ }^{\# \#} p<0.001$. Significant differences between the HFD and HFD+GTE groups: ${ }^{*} \mathrm{p}<0.05$ and ${ }^{* *} \mathrm{p}<0.01$.

Table III. Effects of Geranium thunbergii extract on biochemical parameters in serum of high-fat diet-induced obese mice.

\begin{tabular}{lccc}
\hline & ND & HFD & HFD+GTE \\
\hline Triglyceride (mg/dl) & $78.0 \pm 11.1$ & $88.7 \pm 14.4$ & $41.2 \pm 6.5^{\mathrm{c}}$ \\
Total cholesterol (mg/dl) & $106.7 \pm 1.8$ & $164.8 \pm 2.4^{\mathrm{b}}$ & $140.0 \pm 7.0^{\mathrm{c}}$ \\
LDL-cholesterol (mg/dl) & $4.8 \pm 0.1$ & $6.2 \pm 0.2^{\mathrm{a}}$ & $3.8 \pm 1.1^{\mathrm{d}}$ \\
HDL-cholesterol (mg/dl) & $75.1 \pm 3.2$ & $72.6 \pm 3.8$ & $75.5 \pm 1.7$ \\
AST (U/l) & $66.5 \pm 12.7$ & $86.7 \pm 19.6$ & $72.4 \pm 17.5$ \\
ALT (U/l) & $36.5 \pm 2.5$ & $24.7 \pm 0.8$ & $23.0 \pm 2.2$ \\
Blood urea nitrogen (mg/dl) & $32.5 \pm 0.9$ & $22.0 \pm 1.1$ & $25.4 \pm 2.0$ \\
Creatinine (mg/dl) & $0.45 \pm 0.02$ & $0.41 \pm 0.02$ & $0.37 \pm 0.04$ \\
\hline
\end{tabular}

Values are expressed as the means \pm SE $(n=6)$. Significant differences between the ND and HFD groups: ${ }^{a} p<0.01$ and ${ }^{b} p<0.001$. Significant differences between the HFD and HFD+GTE groups: ${ }^{c} \mathrm{p}<0.05$ and ${ }^{\mathrm{d}} \mathrm{p}<0.01$.

A

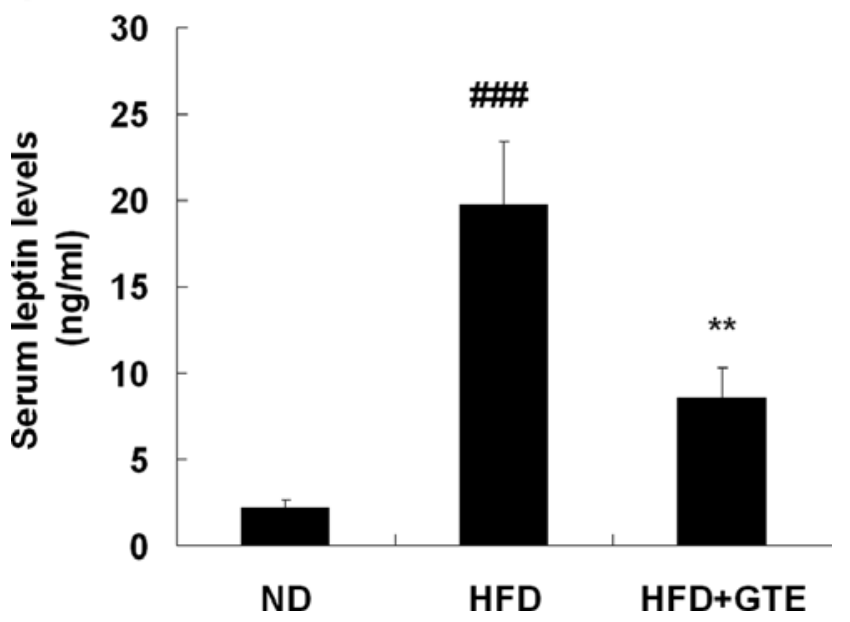

B

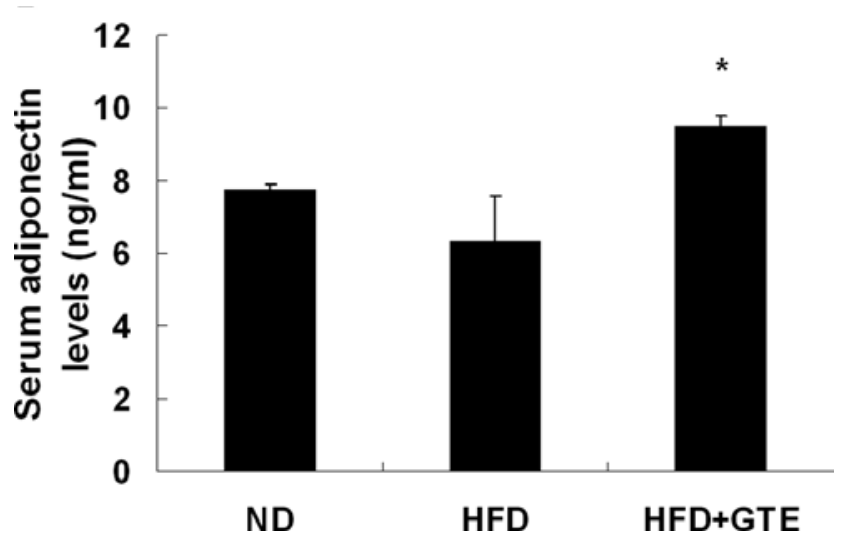

Figure 3. Effect of Geranium thunbergii extract on (A) leptin and (B) adiponectin serum levels in high-fat diet-induced obese mice. ND, normal diet; HFD, high-fat diet; HFD+GTE, high-fat diet + Geranium thunbergii extract. Values are expressed as the means \pm SE ( $n=6$ ). Significant differences between the ND and HFD groups: ${ }^{\# \#}$ p $<0.001$. Significant differences between the HFD and HFD+GTE groups: ${ }^{*} \mathrm{p}<0.05$ and ${ }^{* *} \mathrm{p}<0.01$. 
A

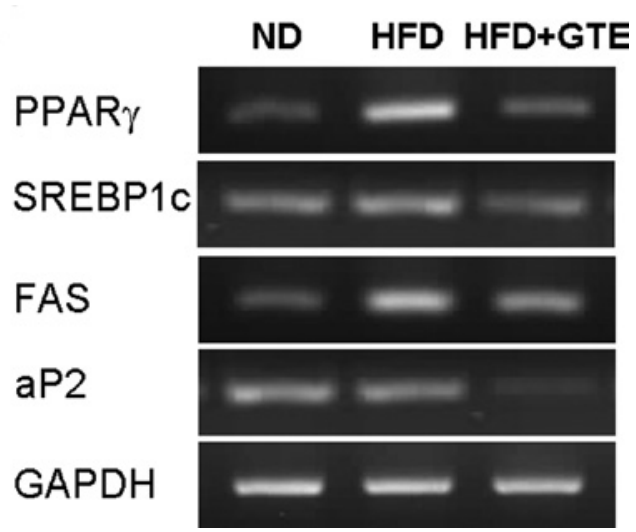

C

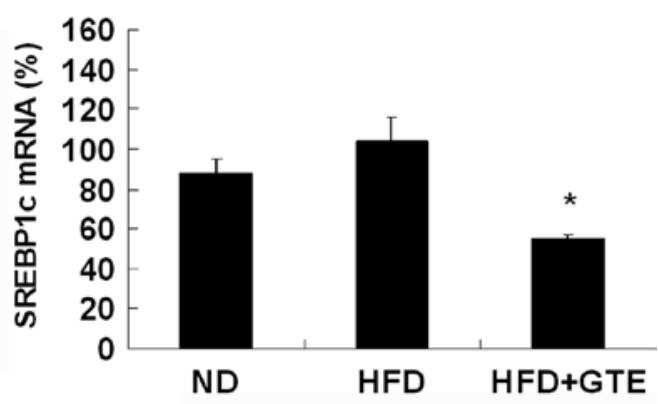

$\mathbf{E}$

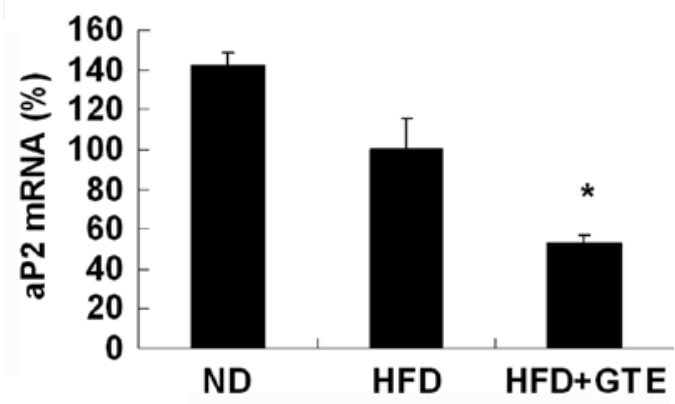

AST, ALT, blood nitrogen urea and creatinine were not significantly changed in GTE-treated mice compared to HFD-fed mice (Table III). Serum levels were in the normal range in all groups according to previously published reports (17-18). Additionally, the GTE-treated mice did not induce significant changes in the weight of liver and spleen (data not shown). These data indicate that administration of $400 \mathrm{mg} / \mathrm{kg} / \mathrm{day}$ of GTE for 6.5 weeks induced no detectable adverse toxic effects in the mice.

Expression of genes involved in lipid metabolism. To understand the mechanism involved in the effects of GTE on lipid metabolism, the expression of lipogenesis-related genes in adipose tissue was investigated (Fig. 4A). Compared to the normal mice, the HFD-induced obese mice had increased mRNA levels of adipocyte markers such as SREBP1c, PPAR $\gamma$ and FAS in the subcutaneous adipose tissue. By contrast, GTE treatment significantly decreased the mRNA expression of SREBP1c, PPAR $\gamma$, FAS and aP2 compared to their levels in the HFD group (Fig. 4B-E).
B

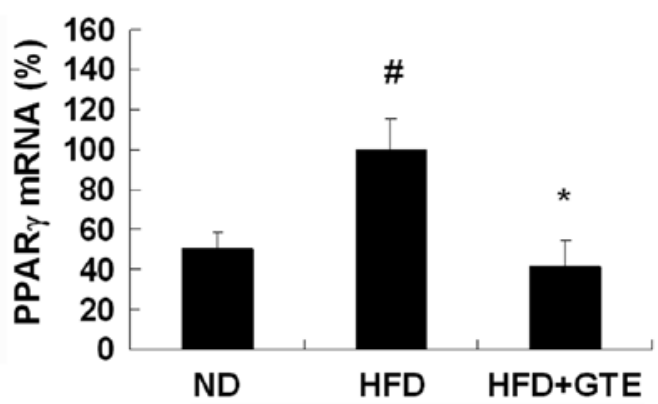

D

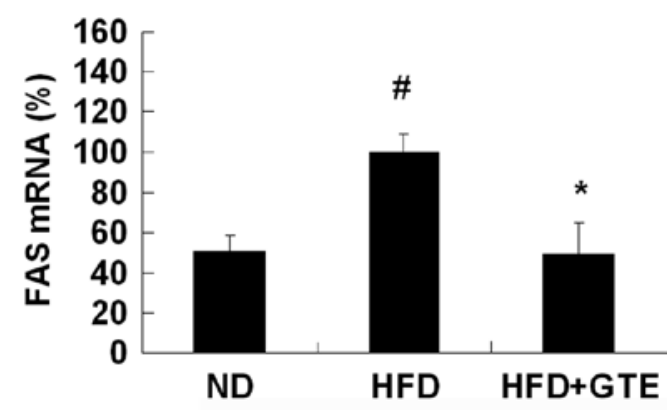

Figure 4. Effect of Geranium thunbergii extract on gene expression in subcutaneous adipose tissue. Representative bands (A), and relative changes (B-E) of mRNA expression. The relative expression levels of genes were normalized using GAPDH as an internal control. ND, normal diet; HFD, high-fat diet; HFD+GTE, high-fat diet + Geranium thunbergii extract. Values are as the means \pm SE $(n=3)$. Significant differences between the ND and HFD groups: $\mathrm{p}<0.05$. Significant differences between the HFD and HFD+GTE groups: ${ }^{*} \mathrm{p}<0.05$.

\section{Discussion}

Obesity is characterized by increased fat mass due to an increase in the size and number of adipocytes that differentiated from preadipocytes (19). In obese conditions, adipocytes accumulate large amounts of lipids and become enlarged. In the present study, GTE treatment inhibited adipose tissue accumulation and adipocyte size as well as decreased body weight gain in HFD-induced obese mice. GTE also reduced triglyceride droplets in differentiated 3T3-L1 cells (data not shown). These results show that GTE may lower adipocyte size by reducing lipid accumulation in 3T3-L1 cells, resulting in decreased adipose tissue mass. PPARs are well-characterized transcription factors that are members of the nuclear hormone receptor superfamily (20). There are three subtypes of PPARs, i.e., $\alpha, \beta, \gamma$, which have distinct tissue distributions. Specifically, PPAR $\gamma$, which is predominantly expressed in adipose tissue, plays a significant role in the regulation of genes involved in adipocyte differentiation, lipid storage and glucose homeostasis (21). PPAR $\gamma$ is known to regulate the transcription of LPL, aP2 and phosphoenolpyruvate carboxykinase in adipose 
tissue (22-23). aP2 is a member of a family of intracellular fatty acid-binding proteins that bind long chain fatty acids with high affinity (24). FAS is a key lipogenic enzyme that catalyzes the biosynthesis of long chain fatty acids from acetyl-CoA precursors (25). Expression of FAS is activated through binding to its promoter region by SREBP1 (26). It has also been reported that SREBP1c activates PPAR $\gamma$ through the production of PPAR $\gamma$ ligands (27). In the present study, GTE treatment in HFD-fed mice markedly decreased the mRNA expression of PPAR $\gamma$, SREBP1c, aP2, and FAS. These results suggest that GTE downregulates the expression of the transcription factor SREBP1c, leading to a reduced expression of PPAR $\gamma, \mathrm{aP} 2$ and FAS to inhibit lipogenesis in adipose tissue.

GTE treatment in the HFD-fed mice also reduced serum triglyceride, total cholesterol, and LDL-cholesterol levels and leptin concentrations. Adipocytes secrete a variety of proteins known as adipokines. The secreted proteins include tumor necrosis factor- $\alpha$, interleukin- 6 , resistin, leptin and adiponectin (28). Leptin plays a crucial role in regulating body weight by controlling the size of adipose tissue. It was reported that plasma leptin concentrations and transcription are directly associated with adiposity and body weight changes in humans and rodents (29). The decreased mass of adipose tissue in GTE-treated mice could be attributed to reduced leptin levels. GTE treatment also increased serum adiponectin levels. Adiponectin is known to contribute to insulin sensitivity and fatty acid oxidation (30). Circulating concentrations of adiponectin are inversely correlated with body mass (31). Therefore, the increase in adiponectin levels following GTE treatment may have ameliorated insulin resistance in obese mice, resulting in decreased serum lipid levels and weight loss.

Chemically, Geranium thunbergii was found to contain tannins and flavonoids, such as geraniin, corilagin, ellagic acid, gallic acid, quercetin, kaempferol, and kaempferol7-rhamnoside (32). Quercetin has been found to improve dyslipidemia and hyperinsulinemia in obese Zuker rats (33). In mice fed with a Western diet, chronic dietary intake of quercetin reduced visceral and liver fat accumulation and improved hyperglycemia, hyperinsulinemia, and dyslipidemia (34). However, further study is needed to clarify the pharmacological mechanisms of GTE and to identify the active substances responsible for its anti-obesity properties.

In conclusion, the administration of GTE significantly reduced body weight gain and adipose tissue accumulation and improved serum total cholesterol, triglyceride, and LDL-cholesterol levels in HFD-induced obese mice. The anti-obesity effects of GTE were mediated by altering serum adipokine levels and downregulating the expression of SREBP1c, PPAR $\gamma, \mathrm{aP} 2$ and FAS in adipose tissue. These results suggest that Geranium thunbergii is useful for treating metabolic diseases such as obesity and hyperlipidemia.

\section{Acknowledgements}

This study was supported by project (2008-0801), 'Discovery of herbal medicine for regulation of lipogenesis and lipolysis,' from Jinan Red Ginseng Oriental Medicine Cluster Corporation which was funded by Ministry for Food, Agriculture, Forestry, and Fisheries of Korea.

\section{References}

1. Shin SS, Jung YS, Yoon KH, Choi S, Hong Y, Park D, Lee H, Seo BI, Lee HY and Yoon M: The Korean traditional medicine gyeongshingangjeehwan inhibits adipocyte hypertrophy and visceral adipose tissue accumulation by activating PPARalpha actions in rat white adipose tissues. J Ethnopharmacol 127: 47-54, 2010.

2. Lei F, Zhang XN, Wang W, Xing DM, Xie WD, Su H and Du LJ: Evidence of anti-obesity effects of the pomegranate leaf extract in high-fat diet induced obese mice. Int J Obes 31: 1023-1029, 2007.

3. Couillard C, Mauriège $P$, Imbeault $P$, Prud'homme $D$, Nadeau A, Tremblay A, Bouchard C and Després JP: Hyperleptinemia is more closely associated with adipose cell hypertrophy than with adipose tissue hyperplasia. Int J Obes Relat Metab Disord 24: 782-788, 2007.

4. Rosen ED, Walkey CJ, Puigserver P and Spiegelman BM: Transcriptional regulation of adipogenesis. Genes Dev 14: 1293-1307, 2000.

5. Bray GA: Drug treatment of obesity. Rev Endocr Metab Disord 2: 403-418, 2001.

6. Park YS, Yoon Y and Ahn HS: Platycodon grandiflorum extract represses up-regulated adipocyte fatty acid binding protein triggered by a high fat feeding in obese rats. World $\mathrm{J}$ Gastroenterol 13: 3493-3499, 2007.

7. Lemaure B, Touché A, Zbinden I, Moulin J, Courtois D, Macé K and Darimont C: Administration of Cyperus rotundus tubers extract prevents weight gain in obese Zucker rats. Phytother Res 21: 724-730, 2007.

8. Ono Y, Hattori E, Fukaya Y, Imai S and Ohizumi Y: Anti-obesity effect of Nelumbo nucifera leaves extract in mice and rats. J Ethnopharmacol 106: 238-244, 2006.

9. Pokharel YR, Liu QH, Oh JW, Woo ER and Kang KW: 4-Hydroxykobusin inhibits the induction of nitric oxide synthase by inhibiting NF-kappaB and AP-1 activation. Biol Pharm Bull 30: 1097-1101, 2007.

10. Hiramatsu N, Xiufen W, Takechi R, Itoh Y, Mamo J and Pal S: Antimutagenicity of Japanese traditional herbs, gennoshoko, yomogi, senburi and iwa-tobacco. Biofactors 22: 123-125, 2004.

11. Ushio Y, Okuda T and Abe H: Effects of geraniin on morphology and function of macrophages. Int Arch Allergy Appl Immunol 96: 224-230, 1991.

12. Xiufen W, Hiramatsu $\mathrm{N}$ and Matsubara M: The antioxidative activity of traditional Japanese herbs. Biofactors 21: 281-284, 2004.

13. Cheng JT, Chang SS and Hsu FL: Antihypertensive action of geraniin in rats. J Pharm Pharmacol 46: 46-49, 1994.

14. Gohar AA, Lahloub ME and Niwa M: Antibacterial polyphenol from Erodium glaucophyllum. Z Naturforsch C 58: 670-674, 2003.

15. Choi H, Eo H, Park K, Jin M, Park EJ, Kim SH, Park JE and Kim S: A water-soluble extract from Cucurbita moschata shows anti-obesity effects by controlling lipid metabolism in a high fat diet-induced obesity mouse model. Biochem Biophys Res Commun 359: 419-425, 2007.

16. Song MY, Lv N, Kim EK, et al: Antiobesity activity of aqueous extracts of Rhizoma Dioscoreae Tokoronis on high-fat diet-induced obesity in mice. J Med Food 12: 304-309, 2009.

17. Han SS, Han HS, Cho KH, Kim YB, Seo JW and Song CW: Studies on the basic data of Ktc: C57BL/6 mice with age: body weight, organ weight, hematology, serum chemistry and urinalysis. Korea J Lab Anim Sci 10: 197-209, 1994.

18. Schnell MA, Hardy C, Hawley M, Propert KJ and Wilson JM: Effect of blood collection technique in mice on clinical pathology parameters. Hum Gene Ther 13: 155-161, 2002.

19. Watanabe T, Hata K, Hiwatashi K, Hori K, Suzuki N and Itoh $\mathrm{H}$ : Suppression of murine preadipocyte differentiation and reduction of visceral fat accumulation by a Petasites japonicus ethanol extract in mice fed a high-fat diet. Biosci Biotechnol Biochem 74: 499-503, 2010

20. Schoonjans K, Staels B and Auwerx J: The peroxisome proliferator activated receptors (PPARs) and their effects on lipid metabolism and adipocyte differentiation. Biochim Biophys Acta 1302: 93-109, 1996.

21. Memon RA, Tecott LH, Nonogaki K, Beigneux A, Moser AH, Grunfeld $\mathrm{C}$ and Feingold KR: Up-regulation of peroxisome proliferator-activated receptors (PPAR-alpha) and PPAR-gamma messenger ribonucleic acid expression in the liver in murine obesity: troglitazone induces expression of PPAR-gammaresponsive adipose tissue-specific genes in the liver of obese diabetic mice. Endocrinology 141: 4021-4031, 2000. 
22. Kliewer SA and Willson TM: The nuclear receptor PPARgammabigger than fat. Curr Opin Genet Dev 8: 576-581, 1998.

23. Spiegelman BM: PPAR-gamma: adipogenic regulator and thiazolidinedione receptor. Diabetes 47: 507-514, 1998.

24. Coe NR and Bernlohr DA: Physiological properties and functions of intracellular fatty acid-binding proteins. Biochim Biophys Acta 1391: 287-306, 1998.

25. Boizard M, Le Liepvre X, Lemarchand P, Foufelle F, Ferré P and Dugail I: Obesity-related overexpression of fatty-acid synthase gene in adipose tissue involves sterol regulatory element-binding protein transcription factors. J Biol Chem 273: 29164-29171, 1998.

26. Magaña MM and Osborne TF: Two tandem binding sites for sterol regulatory element binding proteins are required for sterol regulation of fatty-acid synthase promoter. J Biol Chem 271: 32689-32694, 1996.

27. Kim JB, Wright HM, Wright M and Spiegelman BM: ADD1/ SREBP1 activates PPARgamma through the production of endogenous ligand. Proc Natl Acad Sci USA 95: 4333-4337, 1998.

28. Fasshauer M and Paschke R: Regulation of adipocytokines and insulin resistance. Diabetologia 46: 1594-1603, 2003.
29. Maffei M, Halaas J, Ravussin E, Pratley RE, Lee GH, Zhang Y, Fei H, Kim S, Lallone R and Ranganathan S: Leptin levels in human and rodent: measurement of plasma leptin and ob RNA in obese and weight-reduced subjects. Nat Med 1: 1155-1161, 1995.

30. Rosen ED and Spiegelman BM: Adipocytes as regulators of energy balance and glucose homeostasis. Nature 444: 847-853, 2006.

31. Arita Y, Kihara S, Ouchi N, et al: Paradoxical decrease of an adipose-specific protein, adiponectin, in obesity. Biochem Biophys Res Commun 257: 79-83, 1999.

32. Liu QH, Jeong JE, Choi EJ, Moon YH and Woo ER: A new furofuran lignan from Geranium thunbergii Sieb. et Zucc. Arch Pharm Res 29: 1109-1113, 2006.

33. Rivera L, Morón R, Sánchez M, Zarzuelo A and Galisteo M: Quercetin ameliorates metabolic syndrome and improves the inflammatory status in obese Zucker rats. Obesity (Silver Spring) 16: 2081-2087, 2008.

34. Kobori M, Masumoto S, Akimoto Y and Oike H: Chronic dietary intake of quercetin alleviates hepatic fat accumulation associated with consumption of a Western-style diet in C57/BL6J mice. Mol Nutr Food Res 55: 530-540, 2011. 